\title{
Successful maternal outcome after vaginal delivery in a patient with Eisenmenger Syndrome
}

\author{
Divya Chauhan*, Rachna Agarwal, Prerna Gupta, \\ Gita Radhakrishnan, Ayalur Gopalakrishnan Radhika
}

\begin{abstract}
Department of Obstetrics and Gynecology, University College of Medical Sciences and Guru Teg Bahadur Hospital,
\end{abstract} Delhi, India

Received: 08 January 2018

Accepted: 08 February 2018

\section{*Correspondence:}

Dr. Divya Chauhan,

E-mail: divyachauhan2009@gmail.com

Copyright: () the author(s), publisher and licensee Medip Academy. This is an open-access article distributed under the terms of the Creative Commons Attribution Non-Commercial License, which permits unrestricted non-commercial use, distribution, and reproduction in any medium, provided the original work is properly cited.

\begin{abstract}
Patients with Eisenmenger syndrome are advised against pregnancy. Sometimes patients are diagnosed with Eisenmenger syndrome for the first time during pregnancy. This is what has happened in our case. A primigravida was diagnosed with ventricular septal defect with severe pulmonary artery hypertension for the first time during pregnancy at 34 weeks period of gestation. Management of such patients is challenging with different studies showing variable results. Here we describe such a case which was managed conservatively and was allowed to go into labour spontaneously with vacuum extraction during second stage which subsequently led to a favourable maternal outcome.
\end{abstract}

Keywords: Eisenmenger syndrome, Management, Pregnancy

\section{INTRODUCTION}

When the mean pulmonary artery pressure is greater than $25 \mathrm{~mm} \mathrm{Hg}$ in the setting of normal or reduced cardiac output and a normal pulmonary capillary wedge pressure, it is regarded as pulmonary artery hypertension. ${ }^{1}$ Women with pulmonary artery hypertension owing to any cause have a very high risk of mortality during pregnancy, estimated to be between 30 and 56\%. ${ }^{2}$ Therefore, pregnancy is contraindicated in a patient with pulmonary artery hypertension. ${ }^{3-6}$ If such a patient becomes pregnant, she should be advised termination of pregnancy. ${ }^{7}$ We report an example of a rare situation where heart disease is diagnosed for the first time in pregnancy.

\section{CASE REPORT}

A 22-year-old primigravida presented to emergency at 34 weeks of gestation with complaint of breathlessness for the past 15 days. On examination, she was tachypneic with respiratory rate of 40 per minute. She had tachycardia of 120 beats per minute with blood pressure of $120 / 70 \mathrm{~mm} \mathrm{Hg}$. She was afebrile. Cardiovascular examination was remarkable for a loud P2 and a pansystolic murmur at the left sternal border. Coarse crepitations were heard on both sides in the chest. Her oxygen saturation was $80 \%$ on room air. She also had central cyanosis and bilateral pedal edema. There was no pallor or clubbing. Her jugular venous pressure was raised. Abdomen examination revealed a single live fetus with fundal height corresponding to only 24 weeks gestation. She was not in labour. Her echocardiography showed non-restrictive ventricular septal defect with moderate tricuspid regurgitation and severe pulmonary artery hypertension (pulmonary artery pressure of $75 \mathrm{~mm}$ $\mathrm{Hg}$ ) with ejection fraction of $57 \%$. She was managed conservatively in a propped-up position with high flow oxygen and injection furosemide. However, her oxygen saturation did not improve, and she was intubated. In addition, she was started on nitroglycerine infusion, injection morphine and furosemide infusion. The patient 
improved, and her chest became clear. She went into spontaneous labour after 4 days. Delivery was conducted in ICU with complete pain relief and sedation while the patient was on mechanical ventilation. The delivery was managed with vacuum extraction to minimize the stress of pushing. She delivered a 650-gram fresh stillborn. 40 mg furosemide was given just after delivery. Two days after delivery, she was extubated. She was maintaining oxygen saturation on room air. She was shifted to ward on day 3 and discharged in a stable condition on day 10 postpartum.

\section{DISCUSSION}

Ventricular septal defects are one of the most commonly encountered congenital heart defects. Studies done on newborn infants, including some with no murmurs, found incidence of this heart defect to be from $2 \%$ to $5 \% .8,9$ About $85 \%$ to $90 \%$ of these defects close spontaneously by one year of age. ${ }^{8,10-13}$

In the initial stages, the shunt through the defect is from left ventricle to right. So, there is no cyanosis in the early stage. Eventually, uncorrected VSD leads to progressive increase in pulmonary vascular resistance, thereby leading to reversal of the shunt from right-to-left (Eisenmenger syndrome). This leads to mixing of oxygenated and deoxygenated blood in left ventricle, giving rise to clinical cyanosis.

Pregnancy leads to an increase in the plasma volume and decrease in systemic and pulmonary vascular resistance. This results in an increase in the cardiac output. However, these changes can take place only in healthy pregnant women. Due to the vascular changes occurring in pulmonary artery hypertension, there is failure of the physiological fall in pulmonary vascular resistance. This leads to an elevation of pressure in the right side of the heart, thereby leading to right heart failure, as happened in our patient. The interventricular septum shifts towards the left, thus preventing adequate diastolic filling of the left ventricle and decreasing the cardiac output. There is an increase in right-to-left shunting which aggravates pulmonary vasoconstriction and right heart failure. ${ }^{14,15}$

Among parturients with pulmonary artery hypertension, majority of deaths occur in peri-partum period.2 This is due to the haemodynamic changes which occur in pregnancy and are further exaggerated by the acute changes during labour and delivery. The haemodynamic stress of labour causes hypercarbia and acidosis which leads to acute rise in pulmonary pressures leading to right heart failure. ${ }^{16-19}$

Due to the uterine contractions and loss of blood during delivery, there is huge shift in blood volume. Also, vasovagal reaction to pain, acidosis and hypercarbia associated with vaginal delivery further aggravate the pulmonary artery hypertension. ${ }^{20}$
A similar case of successful outcome after vaginal delivery in a patient of Eisenmenger syndrome has been reported. ${ }^{21}$ In another study, caesarean section was done in 7 patients of Eisenmenger syndrome for deteriorating maternal or fetal condition and it observed that all patients were stable in the postpartum period except one patient who died 30 days after delivery. ${ }^{22}$

It remains a matter of debate as to which mode of delivery is safer for patients with pulmonary artery hypertension and/or congenital heart disease. ${ }^{23}$ Vaginal delivery is associated with less blood loss, fewer bleeding complications, and decreased risk of infection. ${ }^{17,24}$ However, the problem with vaginal delivery is that it is associated with volume changes during contractions. This poses a problem in women with pulmonary hypertension as they have limited capability to increase their cardiac output.

Also, pushing has adverse hemodynamic effects. Therefore, some studies consider planned caesarean delivery to be a better choice. ${ }^{4}$ Caesarean section is necessary in case of maternal haemodynamic deterioration which requires urgent delivery. Volatile agents used for general anesthesia can cause cardiodepression. Also, positive pressure ventilation leads to increased pulmonary vascular resistance. A combined epidural and low-dose spinal anesthesia is good option as it avoids vasodilation. ${ }^{20}$ However, in the present case, patient was allowed spontaneous onset of labour and she delivered vaginally. Second stage of labour was assisted by vacuum extraction to minimize the stress of pushing. Furosemide was given just after delivery to prevent cardiac overload. After delivery, she improved remarkably.

\section{CONCLUSION}

Pregnancy is contraindicated in a patient with pulmonary artery hypertension. If such a patient becomes pregnant, she should be advised termination of pregnancy.

\section{ACKNOWLEDGMENTS}

Authors are thankful to the patient who permitted authors to present her history in this report.

\section{Funding: No funding sources \\ Conflict of interest: None declared \\ Ethical approval: Not required}

\section{REFERENCES}

1. Barst RJ, McGoon MD, Torbicki A, Sitbon O, Krowka M, Olschewski $\mathrm{H}$, et al. Diagnosis and differential assessment of pulmonary arterial hypertension. J Am Coll Cardiol. 2004;43:40S-47S.

2. Weiss BM, Zemp L, Seifert B, Hess OM. Outcome of pulmonary vascular disease in pregnancy: a 
systematic overview from 1978 through 1996. J Am Coll Cardiol. 1998;31:1650-7.

3. Regitz-Zagrosek V, Blomstrom Lundqvist C, Borghi C. ESC guidelines on the management of cardiovascular diseases during pregnancy of the European Society of Cardiology. Eur Heart J. 2011;32:3147-97.

4. Galiè N, Hoeper MM, Humbert M. Guidelines for the diagnosis and treatment of pulmonary hypertension. Eur Heart J. 2009;30:2493-537.

5. Thorne S, McGregor A, Nelson-Piercy C. Risk of contraception and pregnancy in heart disease. Heart. 2006;92:1520-5.

6. Pieper PG. Pre-pregnancy risk assessment and counseling of the cardiac patient. Neth Heart J. 2011;19:477-81.

7. Oakley C, Child A, Jung B, Presbitero P, Tornos P, Klein $\mathrm{W}$, et al. Expert consensus document on management of cardiovascular diseases during pregnancy. Eur Heart J. 2003;24:761-81.

8. Roguin N, Du ZD, Barak M, Nasser N, Hershkowitz $\mathrm{S}$, Milgram E. High prevalence of muscular ventricular septal defect in neonates. J Am Coll Cardiol. 1995;26:1545-8.

9. Sands AJ, Casey FA, Craig BG, Dornan JC, Rogers $\mathrm{J}$, Mulholland HC. Incidence and risk factors for ventricular septal defect in "low risk" neonates. Arch Dis Child Fetal Neonatal Ed. 1999;81:F61-3.

10. Hiraishi S, Agata Y, Nowatari M. Incidence and natural course of trabecular ventricular septal defect: two-dimensional echocardiography and color Doppler flow imaging study. J Pediatr. 1992;120:409-15.

11. Ooshima A, Fukushige J, Ueda K. Incidence of structural cardiac disorders in neonates: an evaluation by color Doppler echocardiography and the results of a 1-year follow-up. Cardiol. 1995;86:402-6.

12. Du ZD, Roguin N, Barak M, Bihari SG, Ben-Elisha M. High prevalence of muscular ventricular septal defect in preterm neonates. Am J Cardiol. 1996;78:1183-5.

13. Du ZD, Roguin N, Wu XJ. Spontaneous closure of muscular ventricular septal defect identified by echocardiography in neonates. Cardiol Young. 1998;8:500-5.

14. Madden BP. Pulmonary hypertension and pregnancy. Int J Obstet Anesth. 2009;18:156-64.

15. Hsu CH, Gomberg-Maitland M, Glassner C. The management of pregnancy and pregnancy-related medical conditions in pulmonary arterial hypertension patients. Int $\mathrm{J}$ Clin Pract. 2011;65(172):6-14.

16. Weiss BM, Hess OM. Pulmonary vascular disease and pregnancy: current controversies, management strategies, and perspectives. Eur Heart J. 2000;21:104-15.

17. Uebing A, Steer PJ, Yentis SM, Gatzoulis MA. Pregnancy and congenital heart disease. Br Med J. 2006;332:401-6.

18. Warnes CA. Pregnancy and pulmonary hypertension. Int J Cardiol. 2004;97(1):11-3.

19. Metcalfe J, Ueland K. Maternal cardiovascular adjustments to pregnancy. Prog Cardiovasc Dis. 1974;16:363-74.

20. Pieper PG, Hoendermis ES. Pregnancy in women with pulmonary hypertension. Neth Heart J. 2011;19:504-8.

21. Kalra P. Vaginal delivery in a patient of Eisenmenger syndrome. Indian $\mathrm{J}$ Med Sci. 2012;66:289-91.

22. Avila WS, Grinberg M, Snitcowsky R, Faccioli R, Da Luz PL, Bellotti G, et al. Maternal and fetal outcome in pregnant women with Eisenmenger's syndrome. Eur Heart J. 1995;16:460-4.

23. Siu SC, Sermer M, Colman JM, Alvarez AN, Mercier LA, Morton BC, et al. Prospective multicenter study of pregnancy outcomes in women with heart disease. Circ. 2001;104:515-21.

24. Steer PJ. Pregnancy and contraception. In: Gatzoulis MA, Swan L, Therrien J, Pantely GA, editors. Adult congenital heart disease: a practical guide. Oxford: BMJ, Blackwell; 2005:16-35.

Cite this article as: Chauhan D, Agarwal R, Gupta P, Radhakrishnan G, Radhika AG. Successful maternal outcome after vaginal delivery in a patient with Eisenmenger Syndrome. Int J Reprod Contracept Obstet Gynecol 2018;7:1262-4. 